\title{
HISTORIA Y PRODUCCIÓN FILOSÓFICA DURANTE EL SIGLO XIX
}

\author{
Teresa Houghton $P$. \\ Gloria Isabel Reyes $C$. \\ Universidad Santo Tomás
}

\section{Resumen}

Este escrito intenta ubicar el origen de la historia de las ideas del siglo XIX en Colombia, en la intención interpretativa de los autores de la segunda mitad del siglo, quienes se proponen dar significación a los hechos de la historia utilizando un aparato conceptual tomado de diversas corrientes ideológicas o filosóficas en boga en la Europa del momento, sin detenerse en el interés puramente descriptivo o historiográfico.

En el siglo XX se continuará el estudio de autores relevantes y la publicación de escritos originales hasta conformar un cierto «canon» de representantes de la intelectualidad decimonónica. La pregunta es por el criterio que orienta la selección y por el «modo» de vincular las ideas en general y las filosóficas en particular al desarrollo de los procesos culturales y sociales. El texto plantea algunas alternativas de trabajo que asumen los aportes de la ciencia del texto y otras disciplinas contemporáneas, y que permitirían abordar el estudio de las ideas del siglo XIX sin caer en las totalizaciones que se han censurado.

\section{Palabras clave}

Bibliografía, filosofía colombiana, historia de las ideas, siglo XIX.

\begin{abstract}
This paper attempts to locate the origin of the history of ideas from XIX century in Colombia, in the interpretative intention of the authors of the second half of the century, who have the intention to give meaning to historical facts using a conceptual structure taken from different ideologies or philosophic currents in vogue at that moment in Europe, without stopping in the purely descriptive or historical interest.
\end{abstract}


In the twentieth century we will be studying relevant authors or publishing their original studies to complete a certain canon of representatives from the intellectuality of the epoch. The question is for the criterion which defines the selection and the mode to vinculate the ideas in general and the philosophical in particular to the development of the cultural and social processes. The paper shows some alternatives of working that take the contributions from the text science and other contemporary disciplines that will take the study of the ideas of the XIX century without totalizing it, which is censurated.

\section{Index terms}

Bibliography, colombian philosophy, history of ideas, XIX century.

\section{Introducción}

La investigación denominada Bibliografía analítica del siglo XIX se inscribe dentro del programa Historia de la filosofía en Colombia, primer proyecto del Centro de Investigaciones de la Facultad de Filosofía de la Universidad Santo Tomás, propuesto por sus fundadores, el Padre Joaquín Zabalza Iriarte y el doctor Germán Marquínez Argote, hace ya más de dos décadas.

El momento histórico, político y social que vivía América Latina en la década de los 70 , los movimientos estudiantiles que se dieron en cascada en Europa y América a partir del "Mayo del 68 francés", el surgimiento de la teología y la filosofía de la liberación, y el nuevo aire dado por esta corriente a la ya existente filosofía latinoamericana, fueron el clima y la coyuntura que, aunados a factores internos de la Facultad de Filosofía, como la huelga estudiantil del 76, la creación de los programas de filosofía a distancia, el afianzamiento de una comunidad académica entusiasta y constituida en grupo de investigación, produjeron efectos tan visibles como la creación de Cuadernos de filosofía latinoamericana, la convocatoria al Primer Congreso Internacional de Filosofía Latinoame- ricana y la creación del Centro de Investigaciones de la Facultad.

Por otra parte, estaba el interés creciente en otros países de la región, como México, Brasil y Argentina, por publicar estudios referentes a su propia historia filosófica, y el empeño de Leopoldo Zea desde la Comisión de Historia del Instituto Panamericano de Geografía e Historia por crear la colección de obras sobre historia de las ideas en América hacia 1956, empeño del cual estuvo ausente Colombia (a pesar de que Jaramillo Uribe preparó para esa ocasión su primera versión de El pensamiento colombiano del siglo XIX), y en 1976 la publicación del mismo Zea de El pensamiento latinoamericano, obra en la cual apenas sí se registra una exigua actividad filosófica en nuestro país. Estos hechos animaron el inicio de la citada investigación que pretendía, en primer lugar, levantar el repertorio de los textos filosóficos escritos en Colombia y, en segunda instancia, recuperar los documentos de difícil consecución y realizar un estudio detallado de los textos con el fin de elaborar la historia de las ideas filosóficas en Colombia.

Para llevar a efecto el primer objetivo el trabajo se dividió por períodos, así: 1) biblio- 
grafía de la Colonia; 2) bibliografía del siglo XIX; y 3) bibliografía del siglo XX. Simultáneamente se inició el trabajo de reseña bibliográfica de la Colonia y del siglo XX; el resultado fue la publicación en 1985 del libro La filosofía en Colombia: bibliografía del siglo $X X$, el cual contiene 2.734 títulos de obras con índices temáticos, y en 1987 se publicó Filosofía en Colombia: bibliografía de los siglos XVI, XVII y XVIII (primera parte), del latinista Rafael Pinzón Garzón, el cual registra 242 manuscritos coloniales con los datos biográficos de sus autores, la descripción del escrito y el sitio de su ubicación. Las dos obras fueron dirigidas por el Centro de Investigaciones y forman parte de la colección Biblioteca colombiana de filosofía, que dirige el Dr. Daniel Herrera Restrepo.

La segunda etapa (recuperación de documentos) se centró preferentemente en los manuscritos coloniales, de los cuales existen 130 fotocopiados y 40 microfilmados. Con esta base se creó un centro de documentación que recogió textos del siglo XIX, colecciones de revistas especializadas y trabajos monográficos referentes a la historia de las ideas. Respecto al mismo objetivo, la Biblioteca colombiana de filosofía ha recogido y publicado la obra de doce autores colombianos acompañada de un estudio introductorio. El análisis de textos y autores ha sido objeto de numerosas tesis de la maestría en filosofía latinoamericana de la Universidad Santo Tomás, así como de varios trabajos profesorales. En relación con la reseña bibliográfica, el profesor Leonardo Tovar dirige la investigación del siglo XX con la pretensión de publicarla por medios magnéticos de manera que pueda ser consultada y actualizada permanentemente.

La reseña bibliográfica del siglo XVIII, segunda parte, y XIX se inició en 1987 con trabajos monográficos sobre los autores más destacados y continuó con la selección de los textos de contenido filosófico. La profesora Teresa Houghton realizó la selección de textos y el estudio introductorio correspondiente al período de la Ilustración en Colombia (siglo XVIII, segunda parte), trabajo que fue también publicado en la Biblioteca colombiana de filosofía con el número 15 en 1990.

El proyecto del siglo XIX se reinició en el 2002 con la revisión del primer documento, asunto que ha resultado dispendioso debido, por una parte, a la dificultad para ubicar, adquirir y consultar algunas fuentes primarias y secundarias y, por otra, a los nuevos criterios de selección resultantes de las actuales discusiones en torno a la naturaleza, pertinencia y métodos de la historia de las ideas. Asunto que tocaremos en alguna medida en este escrito.

Los investigadores se han ocupado además de completar con nuevos datos las listas bibliográficas y las reseñas biográficas de los autores. Preparan igualmente un anexo sobre las publicaciones periódicas del siglo XIX.

En el presente escrito intentaremos revisar la forma como se ha constituido la historia de las ideas del siglo XIX en Colombia, considerar algunos problemas acerca de la selección e interpretación de textos y recoger algunas alternativas de trabajo, incluso ya puestas a prueba por investigadores de nuestro medio académico. Finalmente, presentaremos el estado actual de nuestra investigación.

\section{Historia de las ideas como historia: una crítica al modelo historicista}

El nacimiento y consolidación en América Latina, durante la década de los 40, de la disciplina denominada historia de las ideas tuvo que ver con la preocupación por recuperar 
un pasado intelectual e ideológico y reivindicar dentro de ese pasado una tradición filosófica o, por lo menos, la conexión con alguna vertiente del pensamiento europeo asumida y asimilada en los países de la región.

Lo que caracteriza la historia de las ideas diferenciándola de la historia de la filosofía es su orientación al estudio genérico de las ideas y no sólo al de las ideas filosóficas, como lo reconoció Abellán: "La historia de las ideas es una disciplina relativamente reciente que trata en general de las actividades de la inteligencia humana en cuanto tal... De momento, señalemos que su importancia está en relación con la toma de conciencia del papel que las ideas juegan en el devenir histórico y cultural del hombre"1. Desde este punto de vista, se afirma la relación de las ideas con el desarrollo de la sociedad y de sus procesos históricos y políticos, por una parte, y con sus producciones culturales y espirituales, por otra.

Esta comprensión, profundizada y difundida por José Gaos desde México y Francisco Romero desde Buenos Aires, fue asumida rápidamente por muchos de los estudiosos de la realidad latinoamericana, incluidos los historiadores a secas, y produjo numerosas publicaciones, especialmente en los años 60 y 70. Sobre su aceptación y desarrollo, afirma Javier Sasso: “Transcurridas varias décadas de actividad reconocida en este campo, no tiene ya particular interés mostrar con detalles los innegables méritos de esta historiografía ni explicar por qué su aparición significó un notable avance en un medio poco atento a su pasado intelectual e ideológico; o acostumbrado a referirse a él de manera impresionista y poco fundada”' ${ }^{\text {. Sin }}$ embargo, el mismo autor señala que tiene “ciertos reparos de carácter conceptual con respecto a la organización que estos historiadores del pensamiento latinoamericano han dado a los materiales que investigan, en especial cuando intentan dar una visión global de dicho pensamiento, ubicar en él su vertiente filosófica o insertar a aquél y a ésta en el conjunto de la historia y de la cultura latinoamericana”3.

La primera crítica se refiere al "modelo" que siguen casi todos los historiadores de las ideas ante un texto. Primero lo descubren, después lo describen (a veces minuciosamente) y, por medio de la descripción, lo adscriben a una determinada corriente intelectual que resulta ser de alguna manera una tendencia filosófica. Finalmente, esos materiales son enmarcados en un entorno socio-cultural, casi siempre referido a los hechos políticos en los que muchas veces desaparece el texto.

La segunda crítica completa la estrategia globalizadora de la primera, en cuanto se parte de una periodización que es, en primera instancia, historiográfico-política, a saber: orden colonial, proceso emancipatorio, instauración del nuevo orden, luchas por definirlo y mantenerlo hasta final del siglo XIX. Sobre ésta se construye el orden históricoideológico que atiende a la actividad intelectual preferentemente filosófica y al entorno político y social asignando la periodización de las ideas bien conocida por todos: escolática, romanticismo, positivismo, con la aparición de algunas filosofías, como las de Bentham, Condillac y Tracy, y ya en el novecientos la crítica y superación del positivismo.

ABELLÁN, Luis José. La idea de América: origen y evolución. Madrid: Istmo, 1975, p. 13.

SASSO, Javier. La filosofía latinoamericana y las construcciones de su historia. Caracas: Monte Ávila, 1988.

$3 \quad$ Ibíd., p. 2 
La desconfianza de Sasso no es hacia las imprescindibles estructuraciones históricopolíticas y de las ideas, sino hacia la validez y consistencia de poner a coexistir hechos sociales o políticos con textos, corrientes y autores, lo cual supone asumir como principio epistemológico la frase de sabor hegeliano "la filosofía es la época puesta en pensamiento", lo cual implica aceptar como presupuesto hermenéutico que existen conexiones estructurales entre los distintos planos que integran una sociedad o una cultura, que el plano filosófico actúa como hilo conductor de los procesos y que época y circunstancia local se identifican. Aunque el autor da una extensa explicación y aplicación de sus reparos a la obra de varios historiadores de las ideas, como Zea y Ardao, preferimos quedarnos por ahora con el contenido general de sus críticas en el sentido en que lo permite el caso colombiano.

Ya que la historia de las ideas es antes que todo historia, y puesto que su periodización se ha definido teniendo como referente la historiografía general, veamos precisamente cómo la historia en América Latina nace principalmente como historia política.

El interés que surgió desde la segunda mitad del siglo XIX por la historia en América Latina tiene que ver con la conciencia nacional que fueron adquiriendo ciertas minorías cultas de formación europea, animadas por el deseo de influir ideológica y políticamente en sus contemporáneos. "Saber historia era..., en la segunda mitad del siglo XIX, tener opinión acerca del proceso de constitución del país, o mejor aún, participar en alguna me- dida en el arduo proceso de definición de la nacionalidad"4.

En efecto, el proceso de la independencia había creado un conjunto de países semejantes, por lo cual hallar la peculiaridad de cada uno era una labor muy difícil pero fundamental, no sólo para afirmar su independencia, sino también para justificar su separación de los demás con referencia a los antiguos virreinatos o a conjuntos políticos conformados a raíz de la emancipación. Esa necesidad desencadenó el análisis del pasado y, quizá, la sobrevaloración de personajes y situaciones considerados relevantes para la situación política del momento.

Según José Luis Romero, bajo el influjo de estos intereses nacieron los primeros estudios históricos nacionales cuya prioridad fue el desarrollo político por encima del social, que en esta región, más que en cualquier otra parte del mundo, estuvo ligado a la historia política, ya que conflictos sociales y culturales fueron resueltos, la mayoría de las veces acudiendo a actos de dominación de los grupos en el poder 5 .

En el caso del Nuevo Reino de Granada, la historiografía comienza con las cartas, crónicas y documentos oficiales que dan cuenta de los acontecimientos de la Conquista y la Colonia, y que han sido claves para la investigación histórica posterior. Al respecto, comenta Jorge Orlando Melo ${ }^{6}$, llama la atención cómo, a pesar del carácter doctrinal de tales obras, los cronistas se interesaron por los múltiples aspectos de la vida de las colonias, tales como costumbres, vida cotidiana,

4 ROMERO, José Luis. Situaciones e ideologías en América Latina. Medellín: Universidad de Antioquia , 2001, p. 8.

5 Ibíd., p. 10.

6 Cf. MELO, Jorge Orlando. Historiografía colombiana: realidades y perspectivas. Medellín: Marín Vieco, 1996. 
economía, instituciones, etc., en contraposición con la tendencia presente en obras posteriores, como la Historia de la Revolución en la República de Colombia, de José Manuel Restrepo ${ }^{7}$. Este trabajo histórico contiene los principales acontecimientos políticos del Nuevo Reino durante el siglo XVIII y comienzos del XIX, y un relato detallado del proceso de independencia, las batallas y la primera organización política hasta 1832. El autor centra su atención en los líderes, los enfrentamientos militares y las crisis políticas de este período; en cambio, apenas hace referencia a hechos sociales de trascendencia en la vida nacional. "Lo que era inevitable en Restrepo tuvo un efecto menos deseable en los historiadores subsiguientes que adoptaron la Historia de la Revolución como modelo básico para la escritura de la historia nacional y redujeron la evolución histórica colombiana a la sucesión de luchas militares y de actividades políticas”8.

Otras tres obras históricas aparecen en el siglo XIX: Compendio histórico del descubrimiento y la colonización de la Nueva Granada en el siglo décimo sexto, de Joaquín Acosta, publicada en París en 1848, y La historia eclesiástica y civil de la Nueva Grana$d a$, escrita en 1856 y publicada en 1869 por José Manuel Groot como reacción al tono anticlerical del escrito de Antonio de Plaza Memorias para la historia de la Nueva Granada desde su descubrimiento hasta el 20 de julio de 1810, que había sido publicado en Bogotá en 1850.

En mayor o menor medida son características comunes de las historias mencionadas el privilegiar el recuento descriptivo sobre el interés explicativo o comprensivo, centrarse especialmente en los hechos del siglo XVI y la Independencia, insistir en las virtudes y personajes heroicos y conceder una función moralizante al conocimiento de la historia. Todo esto dio inicio a la tendencia que los críticos han denominado "historiografía tradicional"9.

El interés por el pasado es explicable si reconocemos que ante una realidad caótica e inestable, los historiadores del siglo XIX buscaron en sus orígenes elementos que además de identificar a la nación ofrecieran a su presente una posibilidad de orden y sentido. Es lo que Romero llama "historia comprometida en relación con un problema vivo, pero exclusivamente como historia del desarrollo político” ${ }^{10}$.

Otros textos no considerados propiamente historiográficos hacen explícita esa intencionalidad interpretativa que ha sido calificada negativamente por los historiadores por subordinar la historia a las necesidades de una polémica ideológica.”11. Nos referimos a las obras de José María Samper Apuntamientos para la historia de la Nueva Granada (1853) y Ensayo sobre las revoluciones políticas y la condición social de las repúblicas colombianas (1861). La mencionada polémica giraría en torno a la valoración del legado colonial, siendo en ese momento Samper la visión negativa y el historiador José María Groot el apologista de la herencia española. Al respecto nos interesa destacar, más que el contenido histórico, la intencionalidad interpretativa de Samper, quien intenta, según sus palabras, hacer una "historia filosófica”, ya que "la historia para

\footnotetext{
La obra de Restrepo se publicó originalmente en París en 1827 y luego fue actualizada en Besanzon en 1852. Se reeditó en Bogotá en 1942. La edición que conocemos es de Bedout, 1970, en siete tomos.

8 Ibíd., p. 17.

9 Ibíd., p. 230.

10 ROMERO, Op. Cit., p. 9.

11 MELO, Jorge O. Op. Cit., p. 63.
} 
ser verídica tiene precisión de ser filosófica. Los hechos adquieren para el filósofo y el moralista una importancia inusitada" ${ }^{12}$. El autor aclara que en su trabajo va a emplear un método filosófico que consiste en poner en contraposición las fuerzas del progreso y las de la reacción, las cuales equivaldrían a las categorías de civilización y barbarie.

Dicho esquema le sirve para alinear los hechos en uno u otro bando. La conquista, aunque fue la llegada de la civilización, es un hecho de barbarie; la emancipación fue una acción de progreso y, por lo tanto, de civilización; los cuarenta años de caos son nuevamente barbarie; el último eslabón que encauzó al país por los senderos de la civilización, para completar así la obra de la emancipación, fue la llegada al poder de José Hilario López y el partido liberal el 7 de marzo del 49. Los escritos de Samper estaban orientados a justificar las reformas políticas, económicas y sociales que el partido liberal venía realizando, de manera que no centran su interés en los hechos en sí, sino en su significado; representan, junto con los de Manuel Ancízar, Manuel María Madiedo y Sergio Arboleda ${ }^{13}$, entre otros, el ascenso a otro nivel de la historia, el de la lectura de los hechos a partir de categorías provenientes de doctrinas políticas y filosóficas externas. Ocampo López señala ${ }^{14}$ que las ideas del romanticismo político y del socialismo utópico influyeron en un grupo de intelectuales de la generación liberal de la mitad del siglo
XIX, quienes conocieron los escritos de Luis Blanc, Fourrier, Saint Simon, Proudhon y Condorcet. Por otra parte, los intelectuales de tendencia tradicionalista (Mariano Ospina, José E. Caro, Sergio Arboleda y Miguel A. Caro, entre otros) se interesaron por Jaime Balmes, Donoso Cortés y José de Maistre.

En este mismo nivel de historia se podrían ubicar diversos escritos de Núñez compilados en La reforma política de Colombia, especialmente su escrito "Ensayos de crítica social” o “El Nuevo Mundo”, en el que realiza una interpretación de la historia universal y colombiana a partir de la idea de progreso como paso de lo homogéneo a lo heterogéneo; categorías provenientes del positivismo spenceriano. Puede citarse igualmente su artículo "Las amenazas”, en el que analiza las causas del desorden nacional ${ }^{15}$. Algunos estudiosos han denominado estos escritos como "filosofías de la historia" ${ }^{16}$ por cuanto su interés no está en la narración o descripción de los hechos sino en su interpretación. Si para hacerlo utilizan esquemas y categorías provenientes de filosofías en boga en Europa que se hallaban en proceso de aclimatación entre nosotros, cabe preguntarse por el nivel de generalidad que logran sus modelos interpretativos.

Un caso especial es el de Salvador Camacho Roldán, quien en su famoso discurso de 1882 no sólo reitera la necesidad de hacer una interpretación del presente, sino que presenta

12 SAMPER, José María. Apuntamientos para la historia de la Nueva Granada. Citado por Roberto Salazar en: La filosofía en Colombia: Historia de las ideas. Bogotá: El Búho, 1988, p. 228

13 No es nuestro interés profundizar en este aparte en el contenido de las obras de estos autores. En general se puede decir que, al igual que Samper, se esfuerzan por dar sentido al presente desde la comprensión de la historia como un todo articulado. Aunque los cuatro pertenecen a la generación denominada "Romántica", militan en corrientes de pensamiento diferentes.

14 OCAMPO LÓPEZ, Javier. Colombia en sus ideas. Colección 30 años, Tomo II. Bogotá: Fundación Universidad Central, 1999, p. 715.

15 NÚÑEZ, Rafael. La reforma pública en Colombia. Bogotá: Biblioteca Popular de Cultura Colombiana, 1945.

16 TOVAR, Leonardo. “Trayectoria de la filosofía en Colombia”. En: Pensamiento y Vida N 4, Bogotá, 2000, p. 49. 
la ciencia que brinda los principios con los que debe analizarse la realidad social, política y cultural del país. Esta ciencia, dice Camacho R., "es la sociología, esa nueva rama de la filosofía que la poderosa inteligencia de los griegos del Siglo de Maratón apenas alcanzó a vislumbrar”17.

El siglo XIX, en síntesis, nos presenta tres niveles particulares de la historiografía: 1) el de los protagonistas y testigos; son los autores de las fuentes primarias y origen de las versiones posteriores; 2) el de los narradores, aquellos que iniciaron la periodización y encadenaron los hechos, tal vez en la búsqueda de lo que nos identificaba como nación; una mirada al pasado en función de la problemática de su presente; 3) el de los intérpretes, quienes intentaron dar un sentido global al devenir histórico y lo aplicaron a la situación de la nación; interpretaciones al servicio de proyectos políticos, nos han dicho los historiadores de las ideas.

Es importante insistir en que en el Nuevo Reino de Granada, como en toda América Latina, los períodos de la historia están definidos a raíz de los grandes sucesos políticos y militares, y en que el contenido de la historia decimonónica, como decíamos al iniciar, privilegia estos hechos y en gran medida olvida la historia social.

No se encuentra en el siglo XIX un texto que reúna globalmente el desarrollo de las ideas o su crítica en este período. Se dan reacciones y análisis de las ideas del presente, tales como las críticas de los ilustrados a la enseñanza de la escolástica o la de los antibenthamistas a las posibles consecuencias de esta doctrina, o la de la reacción al positivismo de fin de siglo.

\section{Historia de las ideas filosóficas del siglo XIX y la formación del "canon"}

Los primeros textos que se encuentran en el siglo XX como análisis del siglo XIX son valoraciones de las ideas positivistas de fin de siglo. Desde el Colegio del Rosario, Samuel Ramírez, en su obra La filosofía positivista, hace referencia a los efectos que tuvo en Colombia la moral positivista, y a la lucha sostenida por Miguel Antonio Caro contra la misma ${ }^{18}$. De otro lado, Carlos Arturo Torres dedica el capítulo VIII de su Idola Fori a dar una visión sobre el acontecer filosófico en Colombia y América Latina, y se refiere al carácter de evangelio que el positivismo spenceriano llegó a tener para el grupo del Externado ${ }^{19}$.

El intento de establecer una sucesión y valoración del desarrollo de las ideas filosóficas en el siglo XIX se encuentra en primer lugar en Juan Francisco Franco Quijano (1917), en su artículo "Historia de la filosofía en Colombia”. Allí se hace un recuento de las ideas a través de los textos que se estudiaron en la colonia en el Colegio del Rosario y se registran las principales polémicas ideológicas del siglo XIX. Luis López de Mesa, en Introducción a la cultura colombiana, analiza en 1930 el desarrollo de la cultura desde la Colonia hasta fines del siglo XIX, y destaca el pensamiento de algunos autores como José Eusebio Caro, Miguel Antonio Caro, José María Samper y Rafael Núñez, entre otros. Francisco Renjifo, con su artículo "La filosofía en Colombia” (Colegio del Rosario, 1931), reconstruye el desarrollo intelectual del siglo XIX, como lo hace también Cayetano Betancur en su escrito del mismo

\footnotetext{
17 CAMACHO R., Salvador. Escritos varios. Bogotá: Librería Colombiana, 1895.

18 RAMÍREZ, Samuel. La filosofía positivista. Bogotá, 1898.

19 TORRES, Carlos Arturo. Idola Fori. Bogotá: Biblioteca Popular de Autores Colombianos, 1944.
} 
nombre publicado en la Revista Universidad de Antioquia en 1933.

Luis Eduardo Nieto Arteta, en Economía y cultura en la historia de Colombia (1942) ${ }^{20}$, intenta una lectura del siglo XIX a partir del análisis de las “Memorias de Hacienda”. Este énfasis en la economía le permitirá plantear que el momento de la Emancipación ha de trasladarse de 1810 a 1850 , por considerar que es en este año en el que se dan las mayores transformaciones sociales y económicas del siglo. Los juicios frente a la obra de Nieto Arteta van del entusiasmo por ser el primer texto de historia de la economía propiamente dicho, hasta la crítica al método empleado por reducir la historia económica a lo que le aportan las "Memorias" y otros documentos escritos, sin historiar los procesos económicos y sociales del contexto.

El mérito de la obra frente al tema que nos ocupa está en que representa una ruptura con la historiografía tradicional, basada en acontecimientos políticos exclusivamente, y en que propone interpretar los hechos captando su intencionalidad, según se declara en el prólogo.

En las décadas del 30 y 40 se publicaron y reeditaron documentos y estudios biográficos y críticos sobre algunos autores del siglo anterior, la mayoría en la colección Biblioteca Popular de Cultura Colombiana. Es importante destacar el estudio de Guillermo Hernández de Alba sobre José Félix de Restrepo, publicado en 1935; el de Miguel Samper por Carlos Martínez Silva; de Rafael Núñez por Indalecio Liévano Aguirre; de Rufino Cuervo por Rufino José y Ángel Cuervo; de José Eusebio Caro por Miguel
Antonio Caro; de Antonio Nariño por Jose María Vergara y Vergara; los escritos de Francisco José de Caldas en el Semanario del Nuevo Reino de Granada, y la Reforma política de Núñez, entre otros. También obras de interés general para este período, como Crónicas del Colegio Mayor del Rosario por Guillermo Hernández de Alba, Historia de la literatura colombiana de José María Vergara y Vergara y Periodistas de los albores de la República, publicada en 1946.

Con los trabajos mencionados y la publicación o reedición de fuentes primarias en las colecciones Biblioteca Popular de Cultura Colombiana, Biblioteca Popular de Autores Colombianos y Colección Samper Ortega de Literatura Colombiana del Instituto Colombiano de Cultura, se podría considerar que existía ya un “corpus” de autores y obras reiteradamente aceptadas como portadoras de ideas filosóficas. Sin embargo, será Jaime Jaramillo Uribe quien realice “el primer intento por estudiar de modo sistemático las formas del pensamiento colombiano durante un período amplio" ${ }^{21}$.

Jaramillo Uribe, formado en la Escuela Normal Superior, se licenció en ciencias sociales y económicas. Después de sus frecuentes viajes a Europa se dedicó a hacer de la historia en Colombia una disciplina científica, para lo cual creó la primera carrera de historia en el país y más tarde la revista Anuario colombiano de historia social y de la cultura. Título que refleja su propio proyecto intelectual, ya que se propuso "estudiar la sociedad desde los diversos grupos que la conforman atendiendo a su producción cultural" 22 .

20 NIETO ARTETA, Luis E. Economía y cultura en la historia de Colombia. Biblioteca Básica Colombiana No. 39. Bogotá: Instituto Colombiano de Cultura, 1978.

21 MELO, Jorge Orlando. Op. Cit., p. 25.

22 ARCHILA NEIRA, Mauricio. Jaime Jaramillo Uribe: padre de la Nueva Historia. En: Credencial Historia, julio de 1999, p. 13. 
Aunque sus biógrafos resaltan que en el método y enfoque que empleó se evidencia el conocimiento que tuvo de autores como Durkheim, Marx, Weber y Labrousse, además de Dilthey, Ricker y Cassirer, entre otros, en el prólogo a la primera edición de su libro Pensamiento colombiano del siglo XIX manifiesta su conexión con Leopoldo Zea, a quien agradece su apoyo en la realización de su obra y declara: “(...) registramos un hecho que no puede pasar inadvertido para el historiador de las ideas, si es que la historia de éstas ha de ser el estudio del desarrollo y estructura interna de las formas del pensamiento y sobre todo si se quiere comprender su acción sobre la vida y las instituciones de una nación”23. Palabras en las que se advierte su vinculación intelectual con el movimiento latinoamericano que asumirá la historia de las ideas como la disciplina que pretendía establecer nexos entre las ideas y los diferentes planos de la sociedad en la que se generan.

Ya en su artículo “Tradición y problemas de la filosofía en Colombia”, escrito en 1953, encontramos, como un paréntesis en su análisis de José María Samper, una larga referencia a su concepción de historia de las ideas y de la función de las mismas en la sociedad: “(...) lejos de que la historia de las ideas nos explique la historia misma, la aparición y expansión de una ideología es ya un problema cuya explicación hay que buscar en las formas de existencia con las cuales establece una especie de contrapunto el movimiento de ideas, influyéndose recíprocamente"24. Aunque no es del caso profundizar ahora en este sentido, vale la pena señalar que dicha perspectiva, aunada a las nuevas conceptualizaciones y métodos sobre las relaciones entre historia y cultura, puede servir de pista de análisis para comprender las propuestas de la obra de Jaramillo Uribe. El pensamiento colombiano del siglo XIX, obra escrita en 1956 y publicada en el 64, ofrece un análisis del desarrollo del pensamiento desde el período inmediatamente anterior a la Independencia hasta finales del siglo XIX. Las tres partes de la obra, "Evaluación de la herencia española”, "Estado, sociedad, individuo" y "Pensamiento filosófico”, son complementarias para una comprensión cabal de la dinámica histórica, social e intelectual del período, y efectivamente el autor remite internamente de una parte a otra de su texto.

En cuanto a la tercera parte, "Pensamiento filosófico”, conserva la periodización de la historia ya conocida, y en el campo específico de la historia de las ideas presenta el esquema escolástica-ilustración, benthamismoantibenthamismo, positivismo y neoescolática. Las figuras que aparecen en esta parte son las de Mutis, Caldas y José Félix de Restrepo en la Ilustración; Ezequiel Rojas, Ángel María Galán, Eustaquio Álvarez, y Medardo Rivas en el benthamismo; José Eusebio Caro en la reacción antibenthamista con Miguel A. Caro, a quien dedica un capítulo; José María Samper, Rafael Núñez y Marco Fidel Suárez en el positivismo; y monseñor Rafael María Carrasquilla y sus discípulos de el Rosario en el neoescolasticismo.

El grupo de autores se amplía cuando se refiere al pensamiento político y a la evaluación de la Colonia. Sin embargo, aunque la opción metodológica del autor exija tales

23 JARAMILLO U., Jaime El pensamiento colombiano del siglo XIX . Prólogo a la $1^{\text {a }}$ ed. Obras completas. Bogotá: Alfaomega, 4a. ed., 2001.

24 JARAMILLO URIBE, Jaime. “Tradición y problemas de la filosofía en Colombia”. En: Ideas y valores, 1954. Reimpreso en: Entre la historia y la filosofía. Bogotá: Ed. Revista Colombiana, 1968. 
separaciones, el contexto colombiano del siglo XIX y el origen de los textos sobre los cuales se hace la división de temas remiten a problemas en los que entran en juego posiciones intelectuales que deben recurrir a todo el bagaje con el que cuentan los autores ante un momento determinado de la historia y no sólo a sus convicciones políticas o a sus referentes filosóficos.

Otro aporte importante al estudio del siglo XIX desde la perspectiva de las ideas lo constituye la obra de Javier Ocampo López, doctor en historia, egresado del Colegio de México y del Seminario de Historia de las Ideas en América Latina de la UNAM. En El proceso ideológico de la emancipación” ${ }^{25}$ se dedica al ambiente ideológico que preparó la independencia y al pensamiento de los próceres y libertadores, así como a los primeros intentos de fundamentación política de la nación y las ideas que la sustentaron. En la obra Colombia en sus ideas, de la Colección 30 Años de la Universidad Central, reúne en tres tomos muchos de sus estudios sobre el desarrollo del pensamiento en Colombia en sus diferentes etapas. El segundo tomo (No. 15) está especialmente dedicado a las ideas en el siglo XIX. Algunos de los temas que analiza son: las ideas políticas de los libertadores; las ideas de integración de la Gran Colombia; la ideología de los partidos políticos; las Reformas y la Federación de mitad de siglo; las ideas de las Generaciones Románticas y del Olimpo Radical; la problemática religiosa; una tipología de las Guerras Civiles; y las ideas positivistas y la Regeneración. Aunque la estructuración de sus textos tiene como eje la historia política, su perspectiva es mucho más amplia, según lo declara: "En la historia de las ideas de los individuos y en las mentalidades colectivas, existe una dinámica histórica a través de la cual podemos percibir los cambios, las permanencias, los factores condicionantes, los factores recurrentes o negativos y la vigencia de aquellas ideas que se convierten en fuerza-acción e impulsan a las sociedades”26.

En el estudio sobre el positivismo manifiesta que "no pretende ser una disertación acabada sobre el tema, sino un esbozo de investigación, con cuyo planteamiento se podrá iniciar un estudio... en uno de los aspectos más olvidados de la historia de Colombia cual es la historia de las ideas”27.

En la obra colectiva La filosofía en Colombia: Historia de las ideas ${ }^{28}$, publicada por la Universidad Santo Tomás en 1988, a partir de un estudio sobre la problemática de la historia de las ideas filosóficas se analizan las ideas desarrolladas en la Conquista, la pacificación y la emancipación (las ideas filosóficas en la Colonia y la Ilustración, y los movimientos y polémicas del siglo XIX: benthamismo, Romanticismo, positivismo, tradicionalismo y neoescolástica). Se incluye además un estudio sobre la filosofía en el siglo XX y un análisis de las ideas socialistas en Colombia, así como la recepción de la filosofía latinoamericana. La intencionalidad de la obra, según lo declara Germán Marquínez en el prólogo, no es establecer una comparación con los modelos del pensamiento filosófico europeo, sino dar cuenta de la forma como una intelectualidad de nuestro país en sus distintas etapas ha pensado los

25 OCAMPO L., Javier. El proceso ideológico de la emancipación. Tunja: UPTC, 1974.

26 OCAMPO L., Javier. Colombia en sus ideas. Colección 30 años, No. 15. Bogotá: Ediciones Fundación Universidad Central, 1999, p. 579.

27 Ibíd., p. 803.

28 MARQUÍNEZ, Germán; SALAZAR, Roberto; RODRÍGUEZ, Eudoro; ZABALZA, Joaquín; HERRERA, Daniel y TOVAR, Leonardo. La filosofía en Colombia: Historia de las ideas. Bogotá: El Búho, 1988. 
problemas inherentes a la historia económica, social, política o religiosa. Reconoce que un estudio de las ideas filosóficas está por hacerse y que no existía hasta ese momento una obra que presentara el proceso de las ideas filosóficas desde la conquista hasta el presente en relación con los hechos, lo cual justifica la obra que está prologando.

No se puede desconocer la importancia que para la historia del pensamiento del siglo XIX en Colombia tiene el texto Bibliografía de la filosofía en Colombia, publicado en 1973 por Daniel Herrera, y los trabajos que sobre aspectos y autores específicos han realizado Carlos Valderrama Andrade con sus diversos estudios sobre Miguel Antonio Caro; Gerardo Molina sobre las ideas liberales en Colombia; Herrera Soto sobre el pensamiento conservador; Germán Colmenares sobre el lenguaje de los historiadores del siglo XIX; y las antologías de Oscar Delgado sobre Santander y Azuero, valiosas especialmente por su bibliografía de autores liberales, y de Simón Aljure Chalela sobre José Eusebio Caro y otros autores.

Para este período es importante ver también las memorias de los Congresos de Filosofía Latinoamericana, especialmente el II en 1982 y el IV en 1986, así como las Antologías que reúnen textos por temas y períodos publicadas por la Editorial El Búho.

Cabe destacar la obra Miguel Antonio Caro y la cultura de su época (2002), publicada por la Universidad Nacional como resultado del seminario programado por la Cátedra de Pensamiento Colombiano, recientemente iniciada en esa Universidad, y cuyo objetivo es "promover la investigación en la historia de las ideas y en general de la cultura colombiana”29. En el semestre que culmina, dicho seminario versó sobre "El radicalismo colombiano en el siglo XIX"; la correspondiente publicación será igualmente importante para el estudio de este período.

\section{Selección de los textos y su interpretación}

Abordar el siglo XIX desde la perspectiva de su producción escrita puede tener diversos significados dependiendo de la opción teórica que se asuma frente a la problemática de la selección y la interpretación de los textos, lo cual remite al nivel más general de la concepción misma de la historia de las ideas o a la discusión de su posibilidad.

Sin pretensiones de teorizar al respecto nos proponemos tan sólo presentar algunos aspectos de la problemática que surge de las dos opciones: la historia de las ideas o su negación en la arqueología.

En el primer sentido, partimos de la posición teórica de Abellán con la cual iniciamos este escrito. Para dicho autor la historia de las ideas se orienta en primer lugar a un conjunto genérico de ideas y no sólo a las filosóficas. La historia de las ideas supone, como decíamos, que existe, por una parte, una conexión estructural entre los diversos planos que conforman la sociedad y entre las ideas y los hechos, y por otra, entre estos y las producciones intelectuales, como son los textos escritos.

Las sospechas de Sasso, entonces, apuntarían al temor de la totalización, es decir a la pretensión de encadenar las ideas y los procesos en un todo perfectamente estructurado en el que las ideas filosóficas serían el arconte del saber de la época y actuarían en conso-

29 SIERRA M., Rubén. (ed.). Miguel Antonio Caro y la cultura de su época. Bogotá: Universidad Nacional de Colombia, 2002. 
nancia con los procesos económicos, políticos, religiosos, estéticos y educativos. Así quedaría perfectamente conformada la historia de las ideas de cada una de las etapas ya determinadas por la historiografía general.

En este caso, el peligro reside en la tendencia a forzar las relaciones entre hechos e ideas por el prurito de encontrar una causalidad inmediata, lo cual produce una ilusión de continuidad y orden en el devenir histórico y en el desarrollo del pensamiento. También cabe preguntarse si el nivel de generalidad de la filosofía es suficiente para que en todos los casos sea la columna vertebral del conjunto y por lo tanto la portadora de racionalidad, con exclusión de las ideas que pueden tener mayor relación con la naturaleza de los hechos.

Otro problema en esta perspectiva radica en la dificultad para incluir o excluir un texto del "canon” de una determinada disciplina - en este caso la historia de las ideas filosóficas - dependiendo del grado de fidelidad o distanciamiento que presente con relación al modelo de ideas originarias de las cuales es receptor. Así las cosas, las inevitables variaciones y adaptaciones ocasionadas por los contextos y las circunstancias acarrearían la descalificación de un pensamiento como filosófico.

Una solución posible supondría el excluir los calificativos de las ideas y concederles el nombre genérico de pensamiento de una época o período, reservando, claro está, la denominación de filosofía al ámbito de aquellas ideas que presentan la máxima generalidad, que están conectadas con la tradición y que carecen de intereses ajenos a su propia dinámica. En este sentido, el siglo XIX carecería de textos filosóficos por cuanto las concep- ciones filosóficas que se manejaron sirvieron de sustento a las discusiones políticas, económicas o morales relacionadas con los acuciantes problemas de su agitado entorno.

La arqueología, por su parte, centra su discusión en la autonomía del discurso con relación a su autor, sus influencias o sus antecedentes. No pretende establecer encadenamientos ni continuidades ni descubrir los orígenes o las causas del discurso. Al conceder a cada texto su plena singularidad, hace imposible establecer conexiones que organicen históricamente las ideas. Su propuesta es realizar la descripción intrínseca del texto y descubrir en él su propia racionalidad. Identificar la episteme que hace posible la materialidad de cierto tipo de enunciados, la manera como se articulan y la forma como van configurando una realidad histórica. En el Siglo XIX por ejemplo, se podía asumir la interpretación de un texto como la manifestación de que algunos enunciados o conjuntos teóricos hallan su materialización en ciertas prácticas sociales en la instauración o configuración del Estado en cualquiera de sus etapas.

No ignoramos las críticas y propuestas provenientes de otras corrientes y prácticas interpretativas. Sin embargo, pensamos que lo expuesto por lo menos pone de manifiesto la complejidad de la tarea del investigador de las ideas y la necesidad de replantear su trabajo.

\section{Hacia una propuesta alternativa}

Consideramos que a pesar de los reparos mencionados es posible una historia de las ideas filosóficas del siglo XIX en Colombia si se tienen en cuenta algunas consideraciones: 
1. Para empezar es necesario preguntarse, como sugiere Sasso, qué es lo que ha sido considerado actividad filosófica y filosofía en los distintos contextos en los que se ha utilizado el término, y pensar si más que a filosofías hay que referirse a proyectos de filosofar.

2. La reflexión filosófica en el siglo XIX se forja casi en su totalidad dentro de discusiones políticas, económicas, educativas y morales, y como parte de la fundamentación de posiciones y propuestas, lo cual significa que es muy difícil establecer con total independencia un territorio para cada tipo de ideas.

3. Fuera de los textos (pocos) abiertamente filosóficos, existe un dominio de escritos de interés filosófico por su pretensión de verdad, su grado de generalidad o su conexión con problemas propios de la filosofía.

4. En cuanto a la interpretación, es necesario alejarse tanto de la visión puramente internalista del texto, como de la externalista que atiende sólo a su función social.

5. Las diferentes disciplinas desarrolladas actualmente en torno al texto permiten atender tanto a lo intratextual (plano de su coherencia interna) como a lo intertextual (relación con el cuerpo disciplinar en el cual se inscribe y con otras disciplinas) y a lo extratextual (relación con el contexto y perspectiva pragmática).

6. El reconocimiento del sentido del discurso y de su papel social nos permitirá descubrir la vitalidad y racionalidad, tanto de las prácticas discursivas como de las sociales en mutua relación.

Es esta propuesta la que ha fundamentado el proceso de selección y clasificación de los materiales en el proyecto Bibliografía analítica del siglo XIX. Esperamos que sean estudiados igualmente con ésta o similares perspectivas. 